\title{
Effect of Morinda Tinctoria Leaves Extract on the Corrosion Inhibition of Mild Steel in Acid Medium
}

K. Krishnaveni ${ }^{1)}$, J. Ravichandran ${ }^{1 \dagger \dagger}$ and A. Selvaraj ${ }^{2)}$

1) PG and Research Department of Chemistry, Sri Ramakrishna Mission Vidyalaya College of Arts and Science, Coimbatore-641020, Tamilnadu, India

2) PG and Research Department of Chemistry, CBM College, Coimbatore-641042, Tamilnadu, India

[Manuscript received 19 November 2012, in revised form 9 January 2013]

(c) The Chinese Society for Metals and Springer-Verlag Berlin Heidelberg

\begin{abstract}
The Morinda tinctoria (MT) plant leaves extract was prepared in aqueous and hydrochloric acid media and was used as corrosion inhibitor for mild steel in hydrochloric acid medium. MT is found to be an efficient inhibitor at room temperature and the efficiency decreases with increase in temperature. Results from colorimetric studies predict the amount of iron present in the test solution and the percentage inhibition efficiency values calculated from this data fit well with the weight loss experiments. The AC impedance studies reveal that the mild steel surface is positively charged and the process of inhibition is through charge transfer. Polarisation studies indicate the mixed nature of the inhibitor. Thermodynamic parameters obtained predict that the process of inhibition is a spontaneous one.
\end{abstract}

\section{KEY WORDS: Acid solution; Mild steel; Colorimetry; Electrochemical technique; Corrosion}

\section{Introduction}

Synthetic and naturally occurring plant products are used as corrosion inhibitors. The mechanism of corrosion inhibition process involves formation of a protective layer which prevents the corrosive substance to the metal surface. The selection of the inhibitor is based on the availability, low cost, non-toxic, biodegradable, renewable material and the presence of groups or atoms which aid the adsorption of inhibitor to the metal surface. Plant products satisfy majority of the above criteria and hence a lot of work is being carried out using plant extracts as corrosion inhibitors in different media, on various metals ${ }^{[1-11]}$. Naturally occuring inhibitors from plant products contain a variety of organic substances that may adsorb on the metal surface through hetero atoms, aromatic rings and multiple bonds and thereby prevent the metal surface from further corrosion ${ }^{[12-14]}$. The plant Morinda tinctoria (MT) which belongs to the family of Rubiaceae is a weed which grows on its own in our area and is often discarded as waste. But the leaves of this plant are found to contain many active

\footnotetext{
† Corresponding author. Ph.D.; Tel: +91 422269 2461; Fax: +91 4222693812

E-mail address: jrsrmv@gmail.com (J. Ravichandran)
}

DOI: $10.1007 / \mathrm{s} 40195-012-0219-9$ constituents $^{[15]}$. Available literature suggests that the extract of the plant in any form has not been used for corrosion inhibition studies. Hence, in the present work an attempt has been made to study the corrosion inhibition properties of the aqueous and acid extracts of the leaves of MT on mild steel.

\section{Materials and Methods}

\subsection{Specimen preparation}

The mild steel (MS) specimen of dimension $1 \mathrm{~cm}$ $\times 5 \mathrm{~cm} \times 0.2 \mathrm{~cm}$ with an area of $12.3 \mathrm{~cm}^{2}$ was used for the weight loss study and the specimen with an exposed area of $0.95 \mathrm{~cm}^{2}$ was used for electrochemical study. The surface of the specimens was mechanically polished with different grades $(600,800$ and 1000) of emery papers and then degreased with acetone. The composition (wt.\%) of MS is: C 0.14, Mn 0.57, Al $0.05, \mathrm{Cr} 0.03$, Si $0.02, \mathrm{Cu} 0.01$ and balance is Fe.

\subsection{Extract preparation}

The aqueous and acid extracts were prepared by refluxing 5 and $0.25 \mathrm{~g}$ of dried and powered leaves of MT for $3 \mathrm{~h}$ at $60{ }^{\circ} \mathrm{C}$ in $100 \mathrm{~mL}$ of distilled water and $1 \mathrm{~mol} / \mathrm{L} \mathrm{HCl} \mathrm{respectively.} \mathrm{The} \mathrm{solutions} \mathrm{were} \mathrm{allowed}$ to cool to room temperature, filtered and stored. The 
aqueous and hydrochloric acid extracts are abbreviated as AE and HE respectively. Distilled water and analar grade $\mathrm{HCl}$ were used for preparing the extracts.

\subsection{Weight loss studies}

The pre-cleaned and pre-weighed MS specimens in triplicate were suspended in $100 \mathrm{~mL}$ test solution with and without inhibitor at different concentrations of $\mathrm{AE}$ and $\mathrm{HE}$ in $1 \mathrm{~mol} / \mathrm{L} \mathrm{HCl}$ for a period of $1 \mathrm{~h}$. After that, the specimens were taken out, washed with distilled water, dried and weighed. From the weight loss data, inhibition efficiency (\% IE) was calculated and the critical concentration of the inhibitor was found out for both AE and HE. The effect of halide additives was studied by adding the halide additives $(\mathrm{KCl}, \mathrm{KBr}$ and KI). The influence of the temperature on corrosion behaviour of MS in the presence of MT extract was studied in the range of $\left(30-60^{\circ} \mathrm{C}\right)$. In addition to this the influence of the immersion time on inhibition efficiency was studied by varying the immersion time from 1 to $48 \mathrm{~h}$. All these studies were carried out at $(30 \pm 1){ }^{\circ} \mathrm{C}$. The inhibiting power and corrosion rate were calculated from the following equation.

$$
\% \mathrm{IE}=\left(W_{\mathrm{B}}-W_{\mathrm{I}} / W_{\mathrm{B}}\right) \times 100 \%
$$

where $W_{\mathrm{B}}$ and $W_{\mathrm{I}}$ are the weight loss of the MS specimens in absence and in presence of the inhibitor respectively.

$$
v=87.6 \mathrm{~W} / \rho \mathrm{At}
$$

where $v$ is corrosion rate $(\mathrm{mm} / \mathrm{y}), W$ is the weight loss $(\mathrm{mg}), \rho$ is the density of the specimen $\left(\mathrm{g} / \mathrm{cm}^{3}\right)$, $A$ is the area of specimen $\left(\mathrm{cm}^{2}\right)$ and $t$ is the exposure time (h).

\subsection{Colorimetric estimation}

In the present study, the amount of $\mathrm{Fe}^{2+}$ present in the test solution before and after MS immersion was determined by colorimetric experiment. Ammonium thiocyanate is the colouring agent; the $\% \mathrm{~T}$ (percentage transmittance) of this solution was recorded and used as blank. This was mixed with standard ferric ammonium sulphate solutions of different concentrations and the $\% \mathrm{~T}$ was recorded. A standard graph was plotted between $\% \mathrm{~T}$ and the concentration of $\mathrm{Fe}^{2+}$. MS specimens after weight loss experiments were taken away from the inhibited and uninhibited solutions and were tested for dissolved iron by noting the transmittance after mixing with ammonium thiocyanate. From the standard graph the amount of iron was calculated. The \% IE was calculated from the following equation

$$
\% \mathrm{IE}=\left(C-C^{\prime}\right) / C \times 100 \%
$$

where $C$ is concentration of $\mathrm{Fe}^{2+}$ in blank solution, $C^{\prime}$ is concentration of $\mathrm{Fe}^{2+}$ in inhibited solution.

\subsection{Electrochemical studies}

Electrochemical studies were carried out using electrochemical analyzer of $\mathrm{CH}$ Instrument (Model $608 \mathrm{D})$. The experiments were carried out in a three electrode cell assembly using platinum as auxiliary electrode and calomel as reference electrode. MS specimen was used as a working electrode. AC impendence studies were conducted in the frequency range of $10,000-1 \mathrm{~Hz}$ at the rest potential using $0.02 \mathrm{~V}$ sine wave as the excitation signal. $R_{\mathrm{ct}}$ and $C_{\mathrm{dl}}$ values were obtained from the Nyquist plots and the \%IE was calculated from

$$
\% \mathrm{IE}=\left(R_{\mathrm{ct}}^{i}-R_{\mathrm{ct}}^{\mathrm{o}}\right) / R_{\mathrm{ct}}^{i} \times 100 \%
$$

where $R_{\mathrm{ct}}^{\mathrm{o}}$ and $R_{\mathrm{ct}}^{i}$ are the charge transfer resistance in absence and in presence of inhibitor respectively. Potentiodynamic polarization studies were carried out in the potential range of -0.750 to $-0.250 \mathrm{~V}$ at a scan rate of $0.01 \mathrm{~V} / \mathrm{s}$. The electrochemical parameters such as corrosion current density $\left(I_{\text {corr }}\right)$, corrosion potential $\left(E_{\text {corr }}\right)$, anodic and cathodic slopes $\left(b_{\mathrm{a}}\right.$ and $b_{c}$ ) were obtained from Tafel plots and the \%IE was determined using the formula,

$$
\% \mathrm{IE}=\left(I_{\text {corr }}^{\mathrm{o}}-I_{\text {corr }}^{i}\right) / I_{\text {corr }}^{\mathrm{o}} \times 100 \%
$$

where $I_{\text {corr }}^{\mathrm{o}}$ and $I_{\text {corr }}^{\mathrm{i}}$ are the corrosion current densities in absence and in presence of inhibitor respectively.

\subsection{Surface analysis}

FT-IR was recorded using Perkin Elmer spectrophotometer for the dried HE extract and the material obtained by scrapping the specimens after the immersion experiment. Surface morphology of the mild steel in inhibited and uninhibited systems was also examined using scanning electron microscope (SEM) (JSM 6390).

\section{Results and Discussion}

\subsection{Weight loss studies}

The results obtained for the corrosion inhibition of $\mathrm{MS}$ in $1 \mathrm{~mol} / \mathrm{L} \mathrm{HCl}$ medium with $\mathrm{AE}$ and $\mathrm{HE}$ by weight loss studies are given in Table 1 , and it is clear from the table that the \%IE increases with increasing the concentrations of both AE and HE. The maximum \% IE for $\mathrm{AE}$ and $\mathrm{HE}$ were noticed at the inhibitor concentrations of 12 vol. $\%$ and 15 vol.\%, respectively. The increase in \% IE or decrease in corrosion rate reveals the adsorption of various natural products present in the extract on MS. Table 1 indicates that the \%IE increases with increase in immersion time from 1 to $6 \mathrm{~h}$ and decreases from 24 to $48 \mathrm{~h}$ for $\mathrm{AE}$. In the case of HE the \% IE gradually decreases from 1 to $48 \mathrm{~h}$. The decrease in \% IE after certain period of time might be due to the desorption of inhibitor molecules from the metal surface ${ }^{[16,17]}$. 
Table 1 Effect of the concentration of the inhibitor and immersion period on the corrosion of $\mathrm{MS}$ in $\mathrm{HCl}$ medium

\begin{tabular}{|c|c|c|c|c|c|c|c|c|c|c|c|}
\hline \multirow[t]{3}{*}{ Inhibitor } & \multirow{3}{*}{$\begin{array}{c}\text { Concentration } \\
\quad(\text { vol. } \%)\end{array}$} & \multicolumn{10}{|c|}{ Immersion period } \\
\hline & & \multicolumn{2}{|c|}{$1 \mathrm{~h}$} & \multicolumn{2}{|c|}{$3 \mathrm{~h}$} & \multicolumn{2}{|c|}{$6 \mathrm{~h}$} & \multicolumn{2}{|c|}{$24 \mathrm{~h}$} & \multicolumn{2}{|c|}{$48 \mathrm{~h}$} \\
\hline & & $\begin{array}{c}\mathrm{CR} \\
(\mathrm{mm} / \mathrm{y})\end{array}$ & $\begin{array}{l}\text { \%IE } \\
(\%)\end{array}$ & $\begin{array}{c}\mathrm{CR} \\
(\mathrm{mm} / \mathrm{y})\end{array}$ & $\begin{array}{l}\% \mathrm{IE} \\
(\%)\end{array}$ & $\begin{array}{c}\mathrm{CR} \\
(\mathrm{mm} / \mathrm{y})\end{array}$ & $\begin{array}{l}\text { \%IE } \\
(\%)\end{array}$ & $\begin{array}{c}\mathrm{CR} \\
(\mathrm{mm} / \mathrm{y})\end{array}$ & $\begin{array}{l}\text { \%IE } \\
(\%)\end{array}$ & $\begin{array}{c}\mathrm{CR} \\
(\mathrm{mm} / \mathrm{y})\end{array}$ & $\begin{array}{l}\text { \%IE } \\
(\%)\end{array}$ \\
\hline \multirow[t]{5}{*}{$\mathrm{HE}$} & Blank $\mathrm{HCl}$ & 35.29 & & 25.61 & & 25.90 & & 22.76 & & 15.60 & \\
\hline & 3 & 20.23 & 42.67 & 13.73 & 46.40 & 11.52 & 55.52 & 11.16 & 50.99 & 10.37 & 33.55 \\
\hline & 5 & 10.43 & 70.44 & 8.26 & 67.77 & 8.33 & 67.83 & 6.87 & 69.82 & 7.76 & 50.22 \\
\hline & 10 & 5.90 & 83.29 & 5.50 & 78.51 & 5.62 & 78.28 & 5.75 & 74.72 & 5.66 & 63.73 \\
\hline & 15 & 5.17 & 85.35 & 4.48 & 82.53 & 4.82 & 81.38 & 4.25 & 81.35 & 4.00 & 74.35 \\
\hline \multirow[t]{4}{*}{$\mathrm{AE}$} & 4 & 9.98 & 71.72 & 3.02 & 88.19 & 2.89 & 88.85 & 3.25 & 85.73 & 5.66 & 63.73 \\
\hline & 6 & 7.53 & 78.66 & 1.94 & 92.44 & 1.66 & 93.58 & 2.80 & 87.71 & 5.00 & 67.95 \\
\hline & 8 & 6.26 & 82.26 & 1.84 & 92.80 & 1.63 & 93.70 & 2.92 & 87.16 & 5.11 & 67.24 \\
\hline & 12 & 4.90 & 86.12 & 1.75 & 93.15 & 1.03 & 96.03 & 2.64 & 88.41 & 4.75 & 69.57 \\
\hline
\end{tabular}

Table 2 Effect of addition of halide additives (1 vol.\%) on the corrosion inhibition of MS in $\mathrm{HCl}$ medium

\begin{tabular}{|c|c|c|c|c|}
\hline \multirow[t]{2}{*}{ System } & \multicolumn{2}{|c|}{15 vol. $\% \mathrm{HE}$} & \multicolumn{2}{|c|}{12 vol. $\% \mathrm{AE}$} \\
\hline & $\mathrm{CR}(\mathrm{mm} / \mathrm{y})$ & $\%$ IE (\%) & $\mathrm{CR}(\mathrm{mm} / \mathrm{y})$ & $\% \mathrm{IE}(\%)$ \\
\hline Blank $\mathrm{HCl}$ & 35.29 & & 35.29 & \\
\hline With inhibitor & 5.17 & 85.35 & 4.90 & 86.12 \\
\hline Inhibitor $+\mathrm{KCl}$ & 4.26 & 87.92 & 4.08 & 88.43 \\
\hline Inhibitor $+\mathrm{KBr}$ & 3.63 & 89.72 & 3.08 & 91.26 \\
\hline Inhibitor + KI & 2.72 & 92.29 & 2.18 & 93.83 \\
\hline
\end{tabular}

The effect of halide ions on the inhibition efficiency of various organic compounds and natural products were studied by so many authors ${ }^{[18-20]}$ and they observed that the synergistic effect increased in the order $\mathrm{Cl}^{-}<\mathrm{Br}^{-}<\mathrm{I}^{-}$. According to the literature, the halide ions facilitate adsorption of the organic compounds in plant species during MS corrosion in acidic medium. The increase in the \%IE was observed for MS corrosion in acidic medium with both $\mathrm{AE}$ and $\mathrm{HE}$ in the presence of halide additives and the results are listed in Table 2.

\subsubsection{Effect of temperature}

The effect of the temperature (303-333 K) on corrosion of MS was studied in the presence and in the absence of $\mathrm{AE}$ and $\mathrm{HE}$ to find the nature of interaction between the inhibitor and MS surface. The activation energy $\left(E_{\mathrm{a}}\right)$ for MS corrosion reaction was found out from the slope of the Arrhenius plot $(\operatorname{lgCR} v s$. $1 / T)$ where slope is $-E_{\mathrm{a}} / 2.303 R, \mathrm{CR}$ is the corrosion rate, $E_{\mathrm{a}}$ is the activation energy, $R$ is gas constant, $T$ is temperature in absolute scale. Analysis of Table 3 reveals that in the case of $\mathrm{HE}$ the \% IE decreases considerably when the temperature is increased from 303 to $313 \mathrm{~K}$. This might be due to the desorption of adsorbed inhibitor molecules from the metal surface. However, when the temperature is increased beyond $313 \mathrm{~K}$, the \%IE only slightly decreases. Table 3 also shows that with $\mathrm{AE}$, the $\% \mathrm{IE}$ is almost constant with increase in the temperature indicating that the equilibrium between adsorption and desorption is not altered considerably with increase in the temperature. The difference in the \% IE between AE and HE at dif- ferent temperatures mainly depend on the type and nature of the substituent present in the extract. Since, the \% IE values are altered only to a small extent at higher temperatures; above $313 \mathrm{~K}$ it is obvious that the inhibitor is efficient over a wide range of the temperatures. The calculated values of $E_{\mathrm{a}}$ for both the inhibited systems are found (Table 3 ) to be higher than the uninhibited system. This is an indication of spontaneous adsorption of the inhibitor molecules on MS surface and is attributed to physisorption ${ }^{[21]}$.

\subsubsection{Adsorption isotherm}

Adsorption process is determined by using the surface coverage data and it plays an important role in the prediction of the adsorption isotherm. It also provides information about the nature of interaction between the metal surface and inhibitor. The free energy of adsorption $\left(\Delta G_{\text {ads }}\right)$ at different temperatures was calculated using the following equation.

$$
\Delta G_{\mathrm{ads}}=-R T \ln (55.5 \mathrm{~K})
$$

where $K=\theta / C_{\text {inh }}(1-\theta), \theta$ is surface coverage, $C_{\text {inh }}$ is the concentration of inhibitor. The constant value of 55.5 represents the molar concentration of the water in solution. The values of $\Delta G_{\text {ads }}$ less negative than $-20 \mathrm{~kJ} / \mathrm{mol}$ assumed for physisorption and that more negative than about $-40 \mathrm{~kJ} / \mathrm{mol}$ indicate chemisorption $^{[22]}$. Table 3 shows negative values of $\Delta G_{\text {ads }}$ for both $\mathrm{AE}$ and $\mathrm{HE}$ indicating the stability of the adsorbed layer and spontaneity of adsorption. Observation of the Table 3 shows that in the case of AE, $\Delta H_{\text {ads }}$ is negative and $\Delta S_{\text {ads }}$ is positive. The positive value of $\Delta S_{\text {ads }}$ and negative value of $\Delta H_{\text {ads }}$ indicate the spontaneity of the reaction at all temper- 
Table 3 Effect of the temperature on the corrosion inhibition of MS in $\mathrm{HCl}$ medium with AE and HE

\begin{tabular}{|c|c|c|c|c|c|c|c|c|c|c|c|}
\hline \multirow[t]{3}{*}{ System } & \multicolumn{8}{|c|}{ Temperature (K) } & \multirow{3}{*}{$\begin{array}{c}E_{\mathrm{a}} \\
(\mathrm{kJ} / \mathrm{mol})\end{array}$} & \multirow{2}{*}{$\frac{-\Delta G_{\text {ads }}(\mathrm{kJ} / \mathrm{mol})}{\text { Temperature }(\mathrm{K})}$} & \multirow{3}{*}{$\begin{array}{l}-\Delta H_{\mathrm{ads}} \\
(\mathrm{kJ} / \mathrm{mol})\end{array}$} \\
\hline & \multicolumn{2}{|c|}{303} & \multicolumn{2}{|c|}{313} & \multicolumn{2}{|c|}{323} & \multicolumn{2}{|c|}{333} & & & \\
\hline & $\begin{array}{c}\text { CR } \\
(\mathrm{mm} / \mathrm{y})\end{array}$ & $\begin{array}{l}\text { \%IE } \\
(\%)\end{array}$ & $\begin{array}{c}\text { CR } \\
(\mathrm{mm} / \mathrm{y})\end{array}$ & $\begin{array}{c}\% \mathrm{IE} \\
(\%)\end{array}$ & $\begin{array}{c}\mathrm{CR} \\
(\mathrm{mm} / \mathrm{y})\end{array}$ & $\begin{array}{l}\% \mathrm{IE} \\
(\%)\end{array}$ & $\begin{array}{c}\text { CR } \\
(\mathrm{mm} / \mathrm{y})\end{array}$ & $\begin{array}{l}\% \mathrm{IE} \\
(\%)\end{array}$ & & $\begin{array}{llll}303 & 313 & 323 & 333\end{array}$ & \\
\hline Blank $\mathrm{HCl}$ & 35.29 & & 48.54 & & 87.01 & & 193.06 & & 47.25 & & \\
\hline HE (15 vol. $\%)$ & 5.17 & 85.35 & 11.98 & 75.33 & 21.50 & 75.29 & 50.90 & 73.64 & 61.91 & 7.716 .296 .486 .44 & 18.24 \\
\hline AE (12 vol. \%) & 4.90 & 86.12 & 7.80 & 83.93 & 14.24 & 83.63 & 32.57 & 83.13 & 52.26 & 8.438 .268 .478 .63 & 5.87 \\
\hline
\end{tabular}

atures. This is further supported by the fact that with $\mathrm{AE}$, the \%IE values remain constant in the temperature range of $303-333 \mathrm{~K}$. However, in the case of $\mathrm{HE}$ both $\Delta H_{\text {ads }}$ and $\Delta S_{\text {ads }}$ are negative suggesting the spontaneity of the reaction at lower temperature ${ }^{[23,24]}$. The decrease in the \% IE values at higher temperatures with HE further supports the above argument. Also, the values of $\Delta H_{\text {ads }}$ less negative than $25 \mathrm{~kJ} / \mathrm{mol}$ relate the fact that the process of adsorption is through physisorption ${ }^{[25]}$. The $\Delta G_{\text {ads }}, \Delta H_{\text {ads }}, \Delta S_{\text {ads }}$ values indicate that the process of adsorption of both $\mathrm{AE}$ and $\mathrm{HE}$ are spontaneous and exothermic in nature. Among all the adsorption isotherms tested, Langmuir adsorption isotherm was found to fit well with the experimental data and the isotherm was obtained by plotting, $\lg (\theta / 1-\theta)$ vs. $\lg C$, as shown in Fig. 1 .

\subsection{Colorimetric estimation}

The results obtained from weight loss method give the corrosion rate, \% IE of the inhibitor for MS corrosion and the results obtained from colorimetric estimation give the amount of $\mathrm{Fe}^{2+}$ in the inhibited and uninhibited solutions which can be used to calculate \%IE. The $\% \mathrm{~T}$ values were found out for inhibited and uninhibited solutions after one hour of immersion of the sample in the test solution. The $\% \mathrm{~T}$ values were then used to find out the concentration of $\mathrm{Fe}^{2+}$ in the above solutions using the standard graph. From the $\mathrm{Fe}^{2+}$ concentration, the \%IE

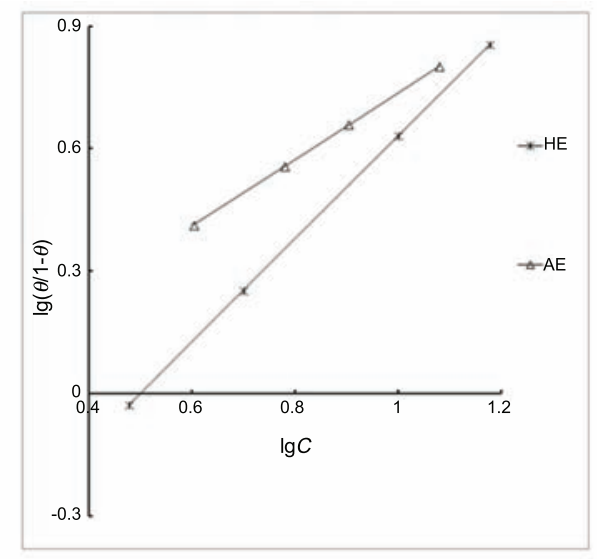

Fig. 1 Langmuir adsorption isotherm for mild steel corrosion in $1 \mathrm{~mol} / \mathrm{L} \mathrm{HCl}$ in the presence of $\mathrm{AE}$ and HE was calculated by applying the relation described in section 2.4 and the results are given in Tables 4 and 5 . Table 4 reveals that with the increase in the concentration of inhibitor, the iron content of the solution after experiment decreases suggesting the lower corrosion rate. Also, the addition of halide salts increases the \%IE (Table 5). The above results predict the adsorption of the inhibitor molecules on the metal surface in the acidic medium thereby prevent the MS from further corrosion. The \% IE value calculated from the colorimetric data is in accordance with the data obtained from weight loss studies.

\subsection{Electrochemical studies}

\subsubsection{AC impedance method}

Impedance studies were carried out by varying the concentration of inhibitors (HE and AE) and the added halide ions. The Randles equivalent circuit used for impedance studies is given in Fig. 2, where $R_{\mathrm{S}}$ is solution resistance, $C_{\mathrm{dl}}$ is the double layer capacitance and $R_{\text {ct }}$ is the charge transfer resistance. The impedance data obtained from Nyquist plots are given in Tables 6 and 7. The representative Nyquist plots for varying the concentration of inhibitor (HE) is given in Fig. 2. The values of $R_{\mathrm{ct}}$ increased with increase in the concentration of inhibitors (HE and $\mathrm{AE}$ ) as well as halide additives and corresponding $C_{\mathrm{dl}}$ values decreased. The increasing $R_{\mathrm{ct}}$ values imply reduced corrosion rate in the presence of the inhibitor and this is because of increasing surface coverage of the inhibitor molecule on the addition. A decrease in $C_{\mathrm{dl}}$ value increases the thickness of the electrical double layer, indicating that the inhibitor is adsorbed on the surface. The impedance diagrams have an approximately semicircular appearance and the diameter of the semicircles were varied upon increasing the concentration of inhibitor suggesting the corrosion of MS is controlled by a charge transfer process ${ }^{[12,14]}$. Also the impedance data were used to find out the potential of zero charge and the results show the positive nature of the specimen.

\subsubsection{Potentiodynamic polarization method}

Fig. 3 depicts the representative Tafel plots of the corrosion inhibition studies on mild steel with different concentrations of HE. The polarisation data obtained are given in Tables 6 and 7 . Results show that the addition of inhibitor alters both $b_{\mathrm{a}}$ and $b_{\mathrm{c}}$ values 
K. Krishnaveni et al.: Acta Metall. Sin. (Engl. Lett.), 2013, 26(3), 321-327.

Table 4 Effect of the concentration of inhibitor on the corrosion of $\mathrm{MS}$ in $\mathrm{HCl}$ medium from colorimetric studies

\begin{tabular}{cccc}
\hline Inhibitor & Concentration (vol.\%) & $C_{\mathrm{Fe}^{2+}}\left(10^{-5} \mathrm{~mol} / \mathrm{mL}\right)$ & \% $\mathrm{IE} \mathrm{( \% )}$ \\
\hline \multirow{3}{*}{$\mathrm{HE}$} & Blank HCl & 7.7630 & 44.35 \\
& 3 & 4.3199 & 71.42 \\
& 5 & 2.2186 & 81.87 \\
$\mathrm{AE}$ & 10 & 1.4074 & 84.70 \\
& 15 & 1.1875 & 71.42 \\
& 6 & 2.2186 & 78.22 \\
& 8 & 1.6908 & 81.87 \\
& 12 & 1.4074 & 87.10
\end{tabular}

Note: $C_{\mathrm{Fe}^{2+}}$ is the concentration of $\mathrm{Fe}^{2+}$ in the test solution

Table 5 Colorimetric data on the effect of addition of halide additives (1 vol.\%)

\begin{tabular}{ccc}
\hline System & $C_{\mathrm{Fe}^{2+}}\left(10^{-5} \mathrm{~mol} / \mathrm{mL}\right)$ & $\% \mathrm{IE}(\%)$ \\
\hline Blank HCl & 7.7630 & \\
$\mathrm{HE}(15$ vol. $\%)$ & 1.1875 & 84.70 \\
$\mathrm{HE}+\mathrm{KCl}$ & 1.0018 & 87.10 \\
$\mathrm{HE}+\mathrm{KBr}$ & 0.8454 & 89.11 \\
$\mathrm{HE}+\mathrm{KI}$ & 0.6255 & 91.94 \\
$\mathrm{AE}(12$ vol. $\%)$ & 1.0018 & 87.10 \\
$\mathrm{AE}+\mathrm{KCl}$ & 0.8454 & 89.11 \\
$\mathrm{AE}+\mathrm{KBr}$ & 0.6255 & 91.94 \\
$\mathrm{AE}+\mathrm{KI}$ & 0.5620 & 92.76 \\
\hline
\end{tabular}

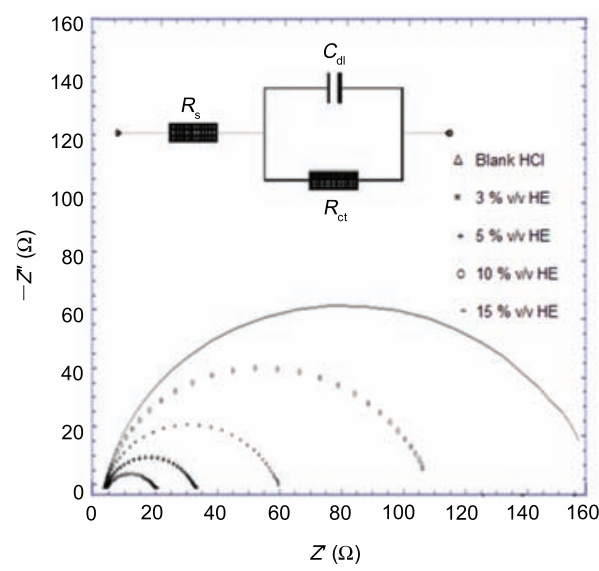

Fig. 2 Nyquist plots for corrosion of MS in $1 \mathrm{~mol} / \mathrm{L} \mathrm{HCl}$ with different concentrations of $\mathrm{HE}$

suggesting that the inhibitor reduces anodic dissolution and retard hydrogen evolution as well indicating the mixed nature of the inhibitor. On increasing the concentration of inhibitors, the $I_{\text {corr }}$ values decrease which are due to the higher surface coverage of the inhibitor $^{[12,14]}$. The results obtained for the synergistic studies are in accordance with the gravimetric data.

\subsection{Surface analysis}

SEM images of uninhibited and inhibited surfaces in Fig. 4 clearly reveal that the surface of the mild steel is covered with inhibitor molecules of AE and HE. This is further confirmed by FT-IR spectroscopy. MT belongs to the same family (Rubiaceae) as that of Morinda citrifolia (MC). The leaves of MC are found to contain many amino acids and

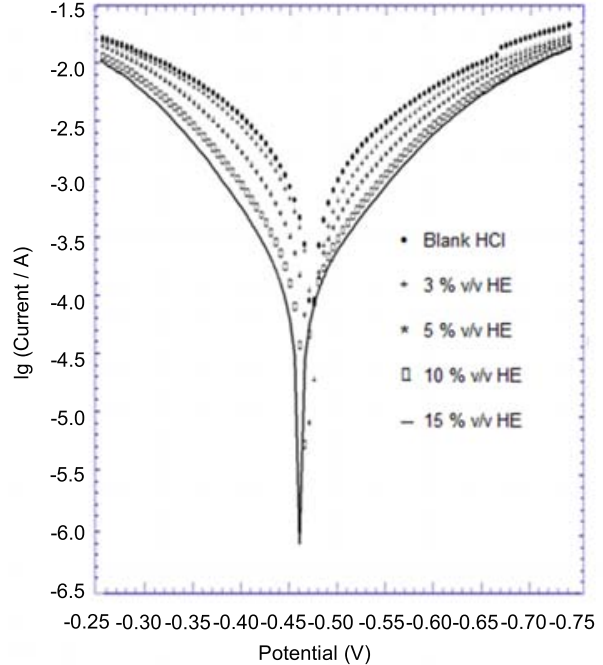

Fig. 3 Tafel plots for MS corrosion in $1 \mathrm{~mol} / \mathrm{L} \mathrm{HCl}$ with different concentrations of $\mathrm{HE}$

flavonoids ${ }^{[26]}$. Hence, the extract of MT is presumed to have many functional groups like $\mathrm{NH}_{2}, \mathrm{COOH}, \mathrm{OH}$, $\mathrm{NH}$ etc. In order to study the nature of adsorption, the IR spectrum (Fig. 5(b)) of scrapped material from the MS specimen coated with HE of MT was compared with that of the crude plant extract (Fig. 5(a)). Two broad peaks at 3368 and $1639 \mathrm{~cm}^{-1}$ in the spectrum of the acid extract can be assigned for $\mathrm{O}-\mathrm{H}$ and/or $\mathrm{NH}_{3}^{+}$symmetric stretching and $\mathrm{C}=\mathrm{O}$ stretching and/or $\mathrm{NH}_{3}^{+}$symmetric bending respectively ${ }^{[27]}$. These peaks have been shifted to 3321 and $1622 \mathrm{~cm}^{-1}$ in the adsorbed material scrapped from the MS, indicating that the inhibitor is adsorbed on the metal surface. The peak at $1261 \mathrm{~cm}^{-1}$ corresponds to $\mathrm{NH}_{3}^{+}$ 
Table 6 Electrochemical parameters for MS corrosion in $1 \mathrm{~mol} / \mathrm{L} \mathrm{HCl}$ at different concentrations of the inhibitor

\begin{tabular}{cccccccccc}
\hline Conc. of inhibitor & $\begin{array}{c}R_{\mathrm{ct}} \\
\left(\Omega \cdot \mathrm{cm}^{2}\right)\end{array}$ & $\begin{array}{c}\% \mathrm{IE} \\
(\%)\end{array}$ & $\begin{array}{c}C_{\mathrm{dl}} \\
\left(\mu \mathrm{F} / \mathrm{cm}^{2}\right)\end{array}$ & $\begin{array}{c}-E_{\text {corr }} \text { vs. SCE } \\
(\mathrm{V})\end{array}$ & $\begin{array}{c}b_{\mathrm{a}} \\
\left(1 / \mathrm{V} \cdot \mathrm{dec}^{-1}\right)\end{array}$ & $\begin{array}{c}b_{\mathrm{c}} \\
\left(1 / \mathrm{V} \cdot \mathrm{dec}^{-1}\right)\end{array}$ & $\begin{array}{c}I_{\text {corr }} \times 10^{-4} \\
\left(\mathrm{~A} / \mathrm{cm}^{2}\right)\end{array}$ & $\begin{array}{c}\% \mathrm{IE} \\
(\%)\end{array}$ \\
\hline \multirow{3}{*}{$\mathrm{HE}$} & Blank HCl & 14.8 & & 540.1 & 0.4769 & 6.768 & 5.787 & 14.470 & \\
& 3 & 26.63 & 44.42 & 301.6 & 0.4783 & 7.617 & 6.470 & 9.160 & 36.70 \\
& 5 & 50.83 & 70.88 & 150.9 & 0.4740 & 8.862 & 7.367 & 4.682 & 67.64 \\
& 10 & 92.16 & 83.94 & 78.33 & 0.4683 & 10.172 & 8.562 & 2.261 & 84.37 \\
$\mathrm{AE}$ & 15 & 136.9 & 89.19 & 74.68 & 0.4641 & 10.979 & 9.290 & 1.436 & 90.08 \\
& 4 & 99.65 & 85.15 & 65.33 & 0.4783 & 10.192 & 8.932 & 2.427 & 83.23 \\
& 6 & 153.1 & 90.33 & 55.41 & 0.4783 & 10.156 & 9.378 & 1.642 & 88.65 \\
& 8 & 179.5 & 91.75 & 51.83 & 0.4801 & 9.854 & 9.509 & 1.404 & 90.30 \\
& 12 & 189.3 & 92.18 & 49.51 & 0.4795 & 9.649 & 9.568 & 1.235 & 91.47 \\
\hline
\end{tabular}

Table 7 Electrochemical parameters for MS corrosion in $1 \mathrm{~mol} / \mathrm{L} \mathrm{HCl}$ with halide additives (1 vol.\%)

\begin{tabular}{|c|c|c|c|c|c|c|c|c|}
\hline System & $\begin{array}{c}R_{\mathrm{ct}} \\
\left(\Omega \cdot \mathrm{cm}^{2}\right)\end{array}$ & $\begin{array}{l}\% \mathrm{IE} \\
(\%)\end{array}$ & $\begin{array}{c}C_{\mathrm{dl}} \\
\left(\mu \mathrm{F} / \mathrm{cm}^{2}\right)\end{array}$ & $\begin{array}{c}-E_{\text {corr }} \text { vs. SCE } \\
(\mathrm{V})\end{array}$ & $\begin{array}{c}b_{\mathrm{a}} \\
\left(1 / \mathrm{V} \cdot \mathrm{dec}^{-1}\right)\end{array}$ & $\begin{array}{c}b_{\mathrm{c}} \\
\left(1 / \mathrm{V} \cdot \mathrm{dec}^{-1}\right)\end{array}$ & $\begin{array}{c}I_{\text {corr }} \times 10^{-4} \\
\left(\mathrm{~A} / \mathrm{cm}^{2}\right)\end{array}$ & $\begin{array}{l}\% \mathrm{IE} \\
(\%)\end{array}$ \\
\hline Blank $\mathrm{HCl}$ & 14.8 & & 540.1 & 0.4769 & 6.768 & 5.787 & 14.470 & \\
\hline HE (15 vol.\%) & 136.9 & 89.19 & 74.68 & 0.4641 & 10.979 & 9.29 & 1.436 & 90.08 \\
\hline $\mathrm{HE}+\mathrm{KCl}$ & 237.9 & 93.78 & 52.86 & 0.4530 & 10.621 & 9.81 & 1.071 & 92.6 \\
\hline $\mathrm{HE}+\mathrm{KBr}$ & 262.6 & 94.36 & 51.59 & 0.4685 & 9.915 & 9.823 & 0.800 & 94.47 \\
\hline $\mathrm{HE}+\mathrm{KI}$ & 277.8 & 94.67 & 50.61 & 0.4782 & 9.797 & 9.943 & 0.905 & 93.75 \\
\hline $\mathrm{AE}(12$ vol. $\%)$ & 189.3 & 92.18 & 49.51 & 0.4795 & 9.649 & 9.568 & 1.235 & 91.47 \\
\hline $\mathrm{AE}+\mathrm{KCl}$ & 267.4 & 94.47 & 48.61 & 0.4769 & 11.147 & 9.592 & 0.994 & 93.13 \\
\hline $\mathrm{AE}+\mathrm{KBr}$ & 284.8 & 94.8 & 47.83 & 0.4783 & 10.822 & 9.839 & 0.875 & 93.95 \\
\hline $\mathrm{AE}+\mathrm{KI}$ & 313.1 & 95.27 & 44.25 & 0.4832 & 10.296 & 9.908 & 0.785 & 94.57 \\
\hline
\end{tabular}

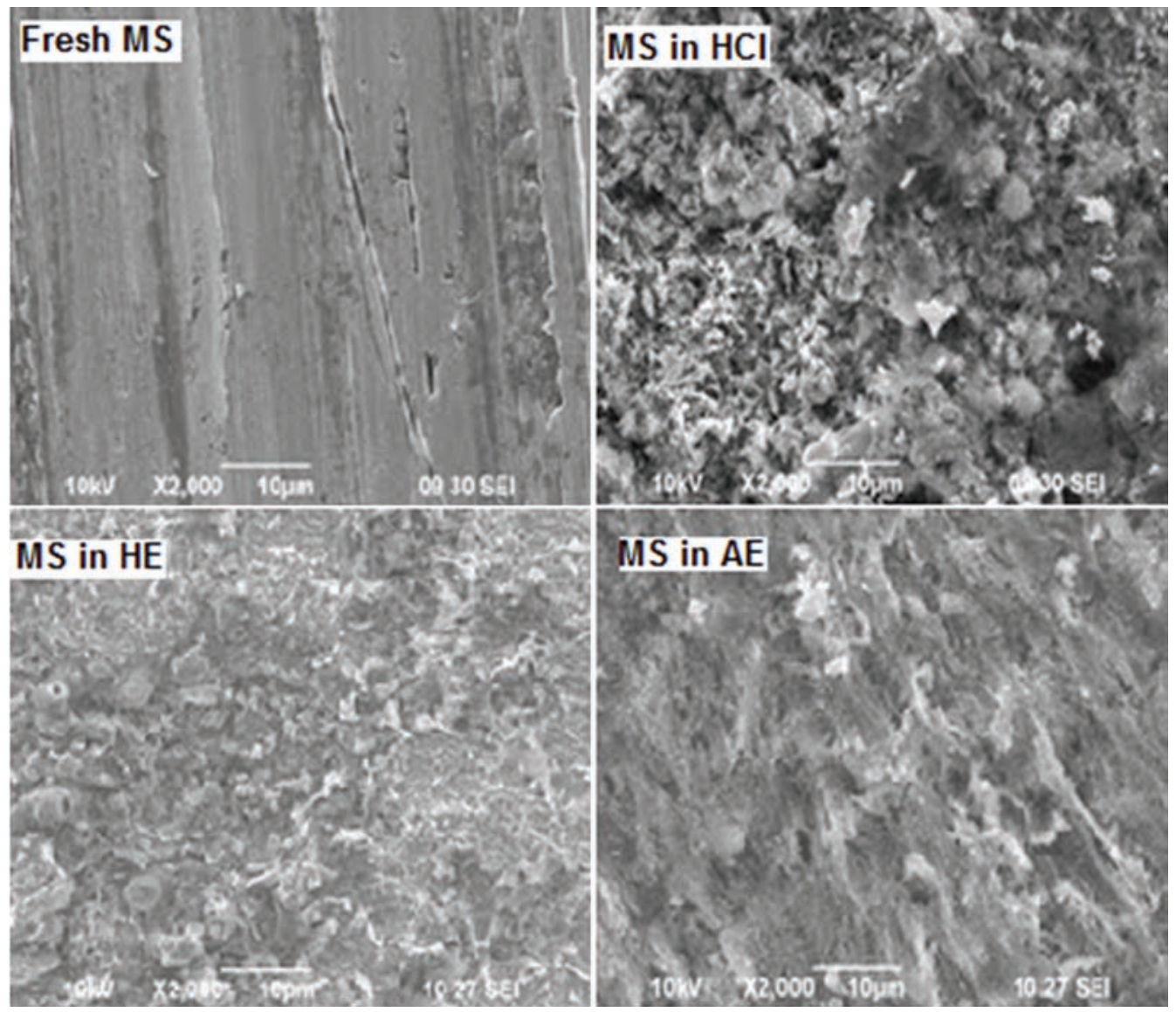

Fig. 4 SEM images of fresh MS sample, MS dipped in $1 \mathrm{~mol} / \mathrm{L} \mathrm{HCl}$, MS dipped in $\mathrm{HE}$ and MS dipped in AE 


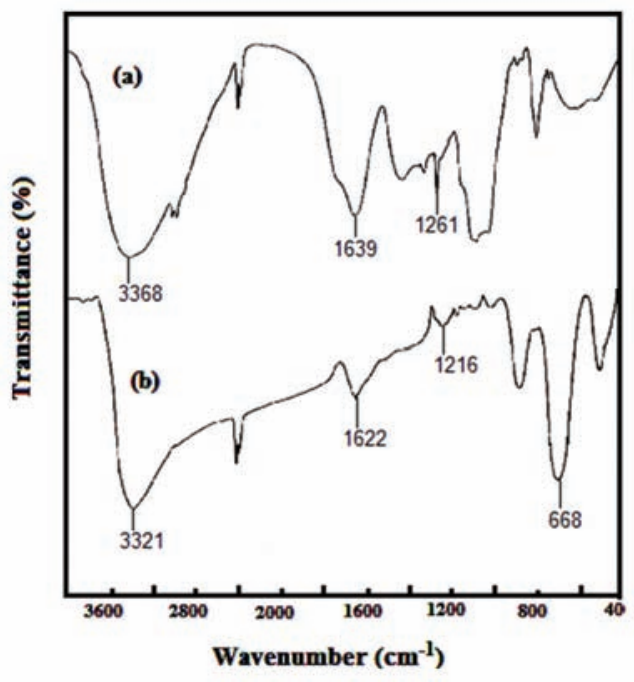

Fig. 5 FT-IR spectrum of the HE (a) and the material scrapped from MS surface (b) after immersion in inhibited system (HE)

in plane bending and/or coupled $\mathrm{C}-\mathrm{O}$ stretching and $\mathrm{O}-\mathrm{H}$ in plane bending vibrations ${ }^{[14,27]}$. The shift of this peak to $1216 \mathrm{~cm}^{-1}$ is again a clear indication of interaction of these groups with the metal surface. The peak at $668 \mathrm{~cm}^{-1}$ in the IR spectrum of the scrapped material is due to $\gamma-\mathrm{Fe}_{2} \mathrm{O}_{3}^{[13,28]}$. The above observations clearly indicate the adsorption of the inhibitor molecule on the mild steel surface at active site.

\section{Mechanism}

The impedance data predicts the positive nature of the specimen in $\mathrm{HCl}$ medium. Also, the thermodynamic data advocate the physisorption mechanism. Further, the adsorption process is found to obey Langmuir adsorption isotherm, suggesting the possibility of multilayer adsorption. Hence, it is reasonable to conclude that while adding the inhibitor to $\mathrm{HCl}$ solution the anions like $\mathrm{COO}^{-}, \mathrm{OH}^{-}$present in the inhibitor solution, and the unshared pair of electrons present on the various hetero atoms present in the functional groups like $\mathrm{C}=\mathrm{O}, \mathrm{O}-\mathrm{H}, \mathrm{N}-\mathrm{H}, \mathrm{NH}_{2}$ gets adsorbed on the MS. It is also possible that the $\mathrm{Cl}^{-}$ ions are adsorbed on the positively charged metal surface followed by the adsorption of positively charged species like $\mathrm{NH}_{3}^{+}$present in the crude extract and thereby preventing the metal surface from further corrosion.

\section{Conclusions}

Morinda tinctoria leaves extract act as effective corrosion inhibitor for mild steel in $\mathrm{HCl}$ medium. The thermodynamic data suggest that the process of adsorption is spontaneous, exothermic in nature and occurs via physisorption. The adsorption of $\mathrm{HE}$ and $\mathrm{AE}$ on MS follow Langmuir isotherm. AC impedance studies favour charge transfer mechanism. Potentiodynamic polarisation studies indicate the mixed nature of the inhibitor. Surface analysis techniques (SEM and FT-IR) also confirm the adsorption of inhibitor molecule on the metal surface. The results from weight loss method are in good agreement with the colorimetric and electrochemical methods.

\section{Acknowledgements}

The authors wish to acknowledge the PG and Research Department of Chemistry, Sri Ramakrishna Mission Vidyalaya College of Arts and Science, Coimbatore20 for providing the facilities.

\section{REFERENCES}

[1] A.Y. El-Etre, Mater. Chem. Phys. 108 (2008) 278.

[2] R.M. Saleh, A.A. Ismail and A.G. El Hosary, Corros. Sci. 23 (1983) 1239.

[3] E.A. Noor, Int. J. Electrochem. Sci. 2 (2007) 996.

[4] G.O. Avwiri and F.O. Igho, Mater. Lett. 57 (2003) 3705.

[5] X.H. Li and S.D. Deng, Corros. Sci. 55 (2012) 407.

[6] S.D. Deng and X.H. Li, Corros. Sci. 64 (2012) 253.

[7] A.I. Ali and N. Foaud, J. Mater. Environ. Sci. 3(5) (2012) 917.

[8] E.E. Oguzie, Corros. Sci. 49 (2007) 1527.

[9] S.A. Umoren, Cellulose. 15 (2008) 751.

[10] P.C. Okafor, M.E. Ikpi, I.E. Uwah, E.E. Ebenso, U.J. Ekpe and S.A. Umoren, Corros. Sci. 50 (2008) 1879.

[11] E.E. Oguzie, Mater. Chem. Phys. 99 (2006) 441.

[12] P.B. Raja and M.G. Sethuraman, Mater. Lett. 62 (2008) 2977.

[13] G. Gunasekaran and L.R. Chauhan, Electrochim. Acta. 49 (2004) 4387.

[14] A.M. Abdel-Gaber, B.A. Abd El-Nabey, I.M. Sidahmed, A.M. El-Zayady and M. Saadawy, Corros. Sci. 48 (2006) 2765.

[15] G. Shanthi, D. Saridha and V. Mariappan, Int. J. Pharm. Pharm. Sci. 4(2) (2012) 636.

[16] S.A. Umoren, I.B. Obot, E.E. Ebenso and N.O. ObiEgbedi, Desalination. 250 (2009) 225.

[17] I.B. Obot and N.O. Obi-Egbedi, Corros. Sci. 52 (2010) 282

[18] G.K. Gomma, Mater. Chem. Phys. 55 (1998) 241.

[19] Y. Harek and L. Larabi, Kem. Ind. 53(2) (2004) 55.

[20] E.E. Oguzie, Mater. Chem. Phys. 87 (2004) 212.

[21] H. Ashassi-Sorkhabi, B. Shaabani and D. Seifzadeh, Appl. Surf. Sci. 239 (2005) 154.

[22] I.B. Obot and N.O. Obi-Egbedi, Corros. Sci. 52 (2010) 198.

[23] Kotz, Treichel, Townsend, General Chemistry, Third Indian Reprint 2011, Indian edn., Cengage Learning India Private Limited, New Delhi, p.669.

[24] D. Ebbing and S.D. Gammon, Fundamentals of Chemistry, First Indian Reprint 2009, Cengage Learning India Private Limited, New Delhi, p.647.

[25] P.W. Atkins, Physical Chemistry, Sixth ed., Oxford University Press, 1998, p.857.

[26] Kirti Singh, World Noni Research Foundation, Int. J Noni Res. Vol-2, No.1-2, Jan-July, 2007, p.17-19, 22.

[27] Jag Mohan, Organic Spectroscopy Principles and Applications, 2nd Ed., Narosa Publishing House, India, 2002, p. 76 .

[28] R. Jasinski and A. Lob, J. Electrochem. Soc. 135 (1988) 551. 